\title{
Full Paper \\ Interventions to promote cancer awareness and early presentation: systematic review
}

\author{
J Austoker', C Bankhead', ${ }^{1,2}$, LJL Forbes ${ }^{*, 3}$, L Atkins ${ }^{3}$, F Martin', K Robb ${ }^{4}$, J Wardle ${ }^{4}$ and AJ Ramirez ${ }^{3}$ \\ 'Cancer Research UK Primary Care Education Research Group, Cancer Epidemiology Unit, University of Oxford, Richard Doll Building, Roosevelt Drive, \\ Oxford, UK; ${ }^{2}$ Department of Primary Care, Oxford Centre for Monitoring and Diagnosis (MaDOx), University of Oxford, Rosemary Rue Building, Oxford, \\ UK: ${ }^{3}$ Kings College London, Cancer Research UK Promoting Early Presentation Group, Institute of Psychiatry, St Thomas' Hospital, London SEI 7EH, UK \\ and ${ }^{4}$ Department of Epidemiology and Public Health, Health Behaviour Research Centre, University College London, Gower Street, London, UK
}

\begin{abstract}
BACKGROUND: Low cancer awareness contributes to delay in presentation for cancer symptoms and may lead to delay in cancer diagnosis. The aim of this study was to review the evidence for the effectiveness of interventions to raise cancer awareness and promote early presentation in cancer to inform policy and future research.

METHODS: We searched bibliographic databases and reference lists for randomised controlled trials of interventions delivered to individuals, and controlled or uncontrolled studies of interventions delivered to communities.

RESULTS: We found some evidence that interventions delivered to individuals modestly increase cancer awareness in the short term and insufficient evidence that they promote early presentation. We found limited evidence that public education campaigns reduce stage at presentation of breast cancer, malignant melanoma and retinoblastoma.

CONCLUSION: Interventions delivered to individuals may increase cancer awareness. Interventions delivered to communities may promote cancer awareness and early presentation, although the evidence is limited.

British Journal of Cancer (2009) I 0 I, S3I - S39. doi: I0.1038/sj.bjc.6605388 www.bjcancer.com

(c) 2009 Cancer Research UK
\end{abstract}

Keywords: cancer awareness; cancer knowledge; delay; complex interventions; early presentation; health service utilisation

Late stage at diagnosis is a major factor accounting for survival differences between European countries for several cancers (Gatta et al, 2000; Sant et al, 2003, 2007). For some cancers, for example breast cancer, late stage at diagnosis has been shown to contribute to the difference in survival between rich and poor (Downing et al, 2007) and black and white women (Jack et al, 2009).

Patient delay in presenting for medical help after symptom discovery is likely to contribute to late stage at diagnosis. Low cancer awareness (which may include knowledge or beliefs about cancer symptoms, risk of developing cancer, risk factors, effectiveness of treatment or effectiveness of strategies for early detection) is a risk factor for patient delay (Ramirez et al, 1999; MacDonald et al, 2004).

In 2003, the Department of Health commissioned a systematic review of evidence about factors influencing delay in cancer diagnosis. While this was not its main focus, it included studies examining effectiveness of interventions to reduce patient delays in cancer diagnosis (MacDonald et al, 2004). It concluded that there had been little research in this area, but that public cancer awareness campaigns had been associated with some improvements in awareness and diagnosis of cancer, but that the long-term benefits were unclear.

The lack of evidence about the effectiveness of interventions to promote cancer awareness and early presentation is hampering development of policy and local action. The aim of this study was

\footnotetext{
*Correspondence: Dr L Forbes; E-mail: lindsay.forbes@iop.kcl.ac.uk
}

to examine the evidence of effectiveness of interventions to raise cancer awareness and promote early presentation with cancer symptoms to inform policy and future research.

\section{MATERIALS AND METHODS}

\section{Search strategy}

We searched the peer-reviewed literature published in English for studies examining the effectiveness of interventions to increase cancer awareness or promote early presentation. We searched the Cochrane Library, Medline, EMBASE and PsychINFO from 2000 to November 2008 (see Appendix A online for search strategy). Two reviewers identified relevant studies from titles and abstracts; a third reviewer resolved disagreements. We checked the reference lists of identified reports for further relevant studies.

\section{Study selection criteria}

We included studies examining interventions in any population except those targeting only people at high genetic risk or aiming to increase cancer awareness in health professionals exclusively. We searched for studies examining effectiveness of two types of intervention:

- Interventions delivered to identified individuals recruited to a study, which attempted to collect outcome data from those 
individuals after the intervention; for example a one-to-one interaction with a health professional or a leaflet given or posted to an identified individual ('individual-level interventions').

- Interventions delivered to communities in which researchers did not control or identify which individual received the intervention, for example media campaigns, leaflets distributed indiscriminately at a health club, street stalls with posters and leaflets to promote early presentation ('community-level interventions').

For individual-level interventions, we searched for randomised controlled trials in which the comparator was placebo, no intervention or usual care. We excluded studies comparing two different interventions or variants of an intervention.

For community-level interventions, we searched for controlled trials (with contemporaneous controls, randomised or nonrandomised, with comparator no intervention) and uncontrolled studies that collected data on outcomes before and after the intervention. This was to acknowledge that evaluating communitylevel interventions in randomised controlled trials is difficult and that policy on implementation of these is often made on the basis of less rigorous evaluations.

We categorised each type of study by whether the outcome related to cancer awareness or early presentation. We included studies with any one of the following cancer awareness outcomes: knowledge or beliefs about cancer symptoms, what to look for when detecting a change that might be cancer, risk of cancer, cancer risk factors, effectiveness of cancer treatment if given early, natural history or prognosis of cancer, attitudes towards early detection behaviours and help seeking or confidence to detect a change that might be cancer. We included studies with any one of the following outcomes that might reflect early presentation: time from symptom discovery to presentation or diagnosis, stage of disease at diagnosis or survival/mortality.

We excluded studies examining exclusively any of the following outcomes: knowledge of or beliefs about nature of treatment for cancer, cancer screening or checking behaviours (for example checking breasts, testicles or skin); health-checking behaviour (for example frequency of or competency in breast, testicular or skin selfexamination); intentions to take up screening or screening uptake. We excluded studies with composite outcomes including the outcomes of interest, where these were not reported separately.

We also excluded studies in which the only post-intervention outcome measure was taken on the same day the intervention was delivered (see Appendix B online for summary of inclusion and exclusion criteria).

Two reviewers independently extracted data from all papers identified as potentially relevant onto a data extraction form (Appendix $\mathrm{C}$ online). Two reviewers independently applied the inclusion criteria and a third reviewer resolved disagreements.

\section{Quality assessment}

The quality of randomised controlled trials eligible for inclusion in the review was scored using a methodology checklist developed previously by members of the review team (Goldsmith et al, 2006) (Appendix D online provides the form used by reviewers to measure quality). Each criterion on the checklist was assessed as well covered, adequately addressed, poorly addressed, not reported or not applicable. The methodological quality of each study was then rated as: ++ (all or most of the criteria have been fulfilled), + (some of the criteria have been fulfilled) or - (few or no criteria have been fulfilled). We did not formally score quality of studies of community-level interventions.

\section{Data synthesis}

We conducted non-quantitative synthesis of evidence by preparing tables summarising the results of studies for each of the main outcomes of interest.

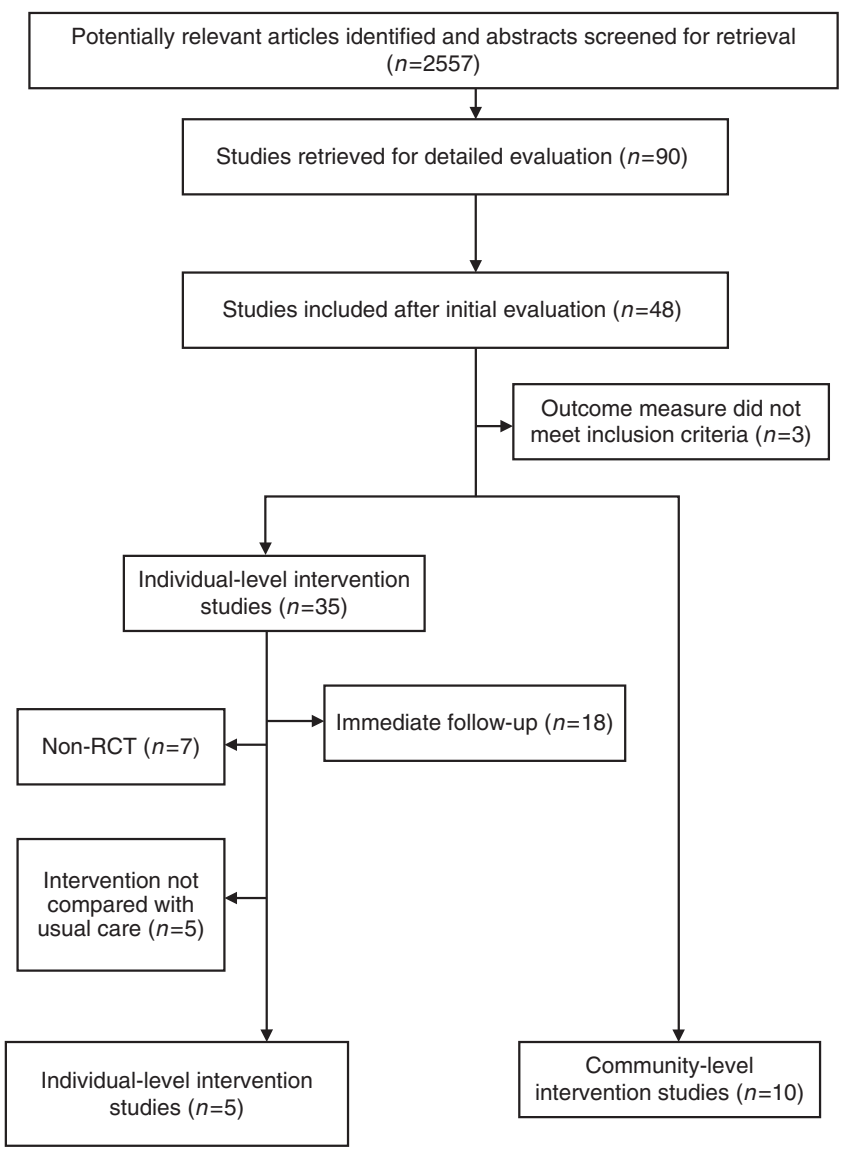

Figure I Flow of studies.

\section{RESULTS}

The search strategy identified 2557 abstracts. Of these, 90 were identified as meeting the criteria and we obtained full text versions of these reports. We subsequently found that 42 of these were not relevant. We excluded three out of the remaining 48 reports because the outcomes did not meet the inclusion criteria. This left 35 studies of individual-level interventions and 10 of communitylevel interventions. From the individual-level interventions, we excluded 18 because outcomes were measured on the same day as the delivery of the intervention, 7 because they were not randomised controlled trials and 5 because the studies compared interventions with other interventions, rather than no intervention or usual care (Figure 1).

\section{Individual-level interventions}

We found five randomised controlled trials of individual-level interventions examining cancer awareness outcomes and none examining early presentation outcomes.

Description of studies and interventions The five randomised controlled trials were carried out in the United Kingdom, United States and the Netherlands and are described in Table 1. Two were cluster randomised controlled trials (Boundouki et al, 2004; Glazebrook et al, 2006). The trials focused on all cancers (de Nooijer et al, 2004), prostate cancer (Wilt et al, 2001), breast cancer (Rimer et al, 2002), oral cancer (Boundouki et al, 2004) and malignant melanoma (Glazebrook et al, 2006). Four of the trials examined the effectiveness of written information compared with no written information, either sent by post (Wilt et al, 2001; Rimer 


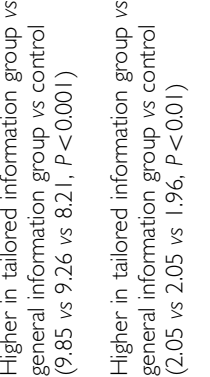
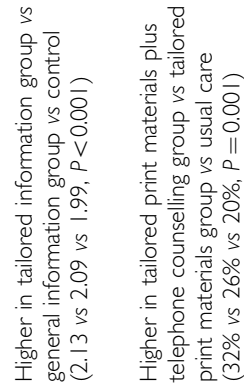

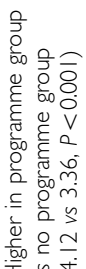
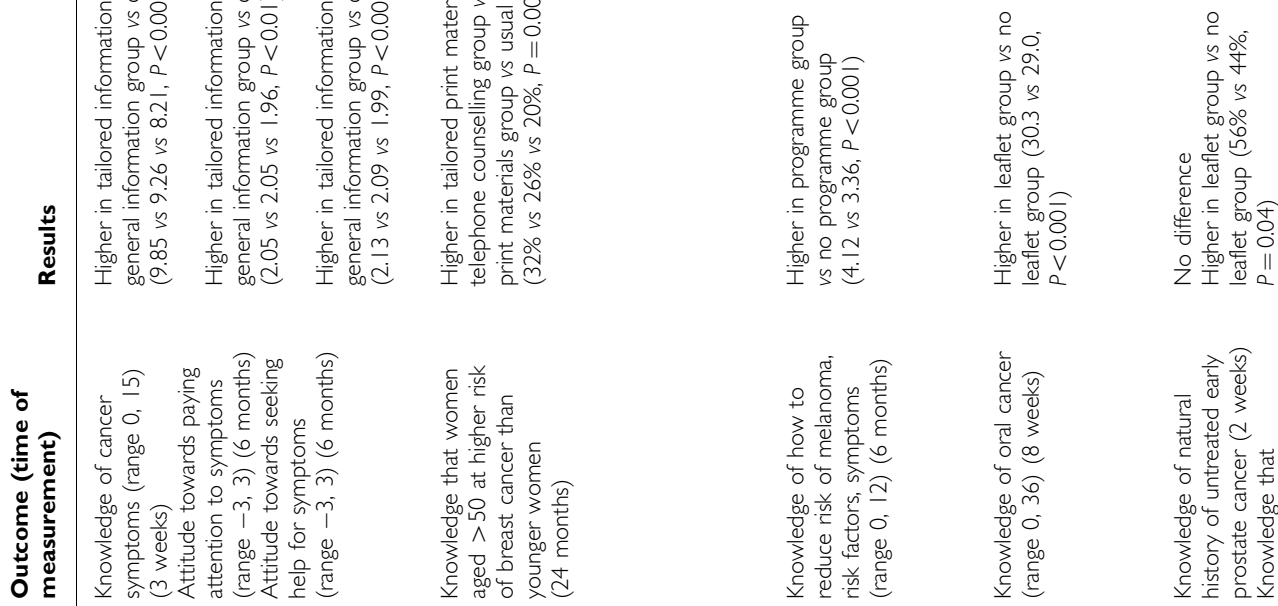

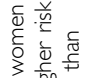

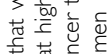

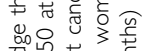

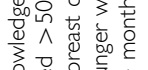

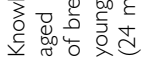

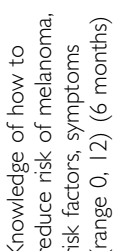

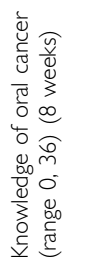

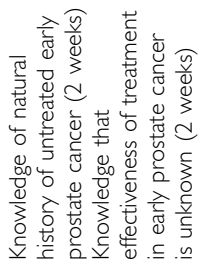

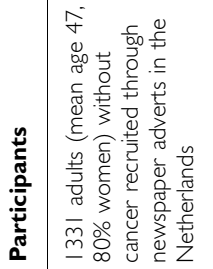

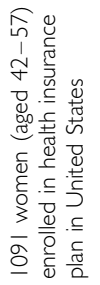

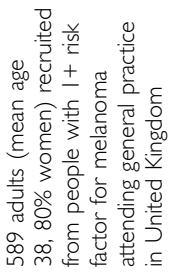

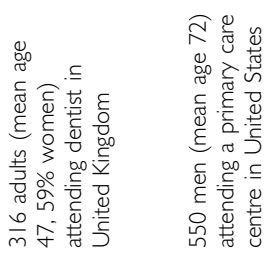

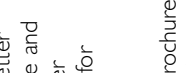

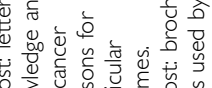

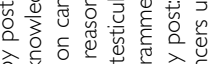

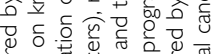

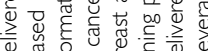

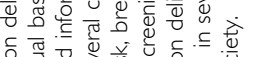

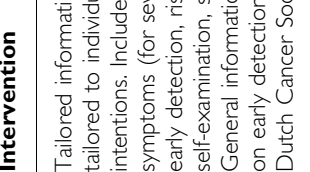
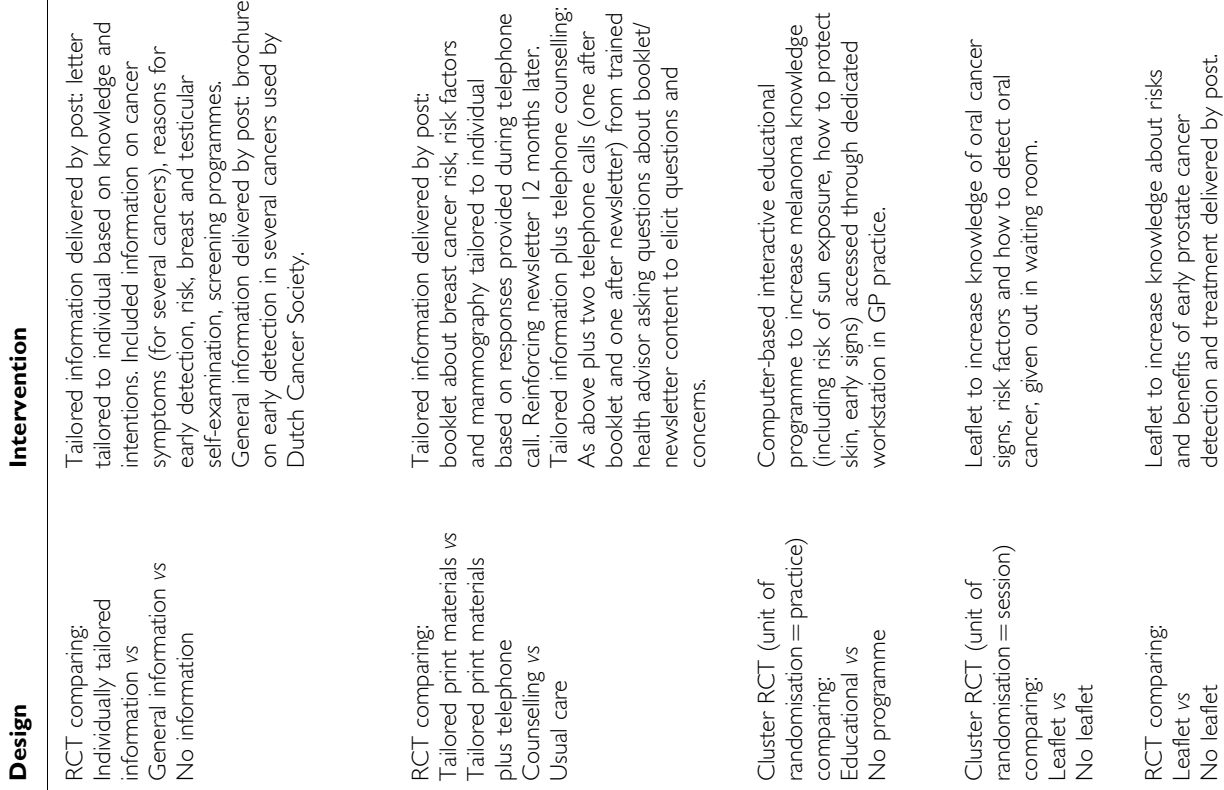

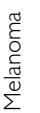

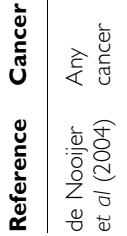

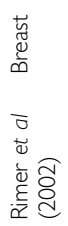
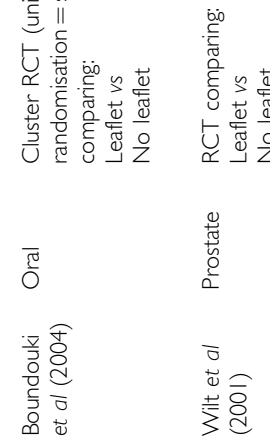
et al, 2002; de Nooijer et al, 2004) or given out in a waiting room (Boundouki et al, 2004). In one trial, the written information was supplemented by telephone counselling in a third arm (Rimer et al, 2002). Another trial examined the additional effect of tailoring the postal information to individual knowledge and intentions in a third arm (de Nooijer et al, 2004). The fifth study examined the effectiveness of an interactive computer programme in general practice (Glazebrook et al, 2006). All trials examined knowledge outcomes, but at different times after the intervention: 2 weeks (Wilt et al, 2001), 3 weeks (de Nooijer et al, 2004), 8 weeks (Boundouki et al, 2004), 6 months (de Nooijer et al, 2004; Glazebrook et al, 2006) and 24 months after (Rimer et al, 2002). All used different measures of cancer knowledge: three used knowledge scores encompassing a range of elements of knowledge (Boundouki et al, 2004; de Nooijer et al, 2004; Glazebrook et al, 2006); one study examined attitudes towards paying attention to and seeking help for symptoms (de Nooijer et al, 2004) and two used only one or two isolated knowledge questions, among other questions relating to screening and treatment preferences (Wilt et al, 2001; Rimer et al, 2002). For one of these studies (Rimer et al, 2002), this is likely to be because the main aim of the intervention was to promote uptake of breast screening, and for the second, the main aim was to inform decision making about screening, rather than to promote early presentation (Wilt et al, 2001).

Quality of studies The quality of the five trials was moderate to good. All stated that they used randomisation, although only one described how the randomisation sequence was generated (Wilt et al, 2001). The nature of the interventions meant that participants could not be kept blind to treatment allocation. None of the trials reported blinding of researchers to treatment allocation at the time of outcome data collection or analysis. All the studies examined baseline demographic differences between the trial arms and all examined change in knowledge or attitude score before and after the interventions except for one (Wilt et al, 2001), which examined outcomes only post-intervention. This may be important because there were baseline differences between the groups in this trial. All the reports reported withdrawals from the trial. The analysis was appropriate for most studies, except one cluster randomised controlled trial, which did not analyse the data using the appropriate method for this design (Boundouki et al, 2004). The other cluster randomised controlled trial used appropriate random effects modelling (Glazebrook et al, 2006).

Findings The trials were heterogeneous in terms of nature of intervention, populations and outcomes measured and, therefore, we did not attempt any quantitative synthesis. All the five trials found that the intervention increased at least one aspect of cancer awareness, although the effects were fairly modest. The most intensive intervention - tailored written information with a reinforcing newsletter at 12 months plus two telephone counselling sessions - increased the proportion who gave the correct answer to a question about age-related risk by $12 \%$ compared with usual care 2 years after the written information is sent (Rimer et al, 2002). Less intensive interventions increased cancer awareness more modestly (an interactive computer programme increased the average melanoma knowledge score by $6 \%$ after 6 months (Glazebrook et al, 2006) and a leaflet increased average oral cancer knowledge score by $4 \%$ after 8 weeks (Boundouki et al, 2004)). A leaflet about prostate cancer increased the proportion who knew that the effectiveness of treatment in early prostate cancer is unknown by $12 \%$ after 2 weeks, but the magnitude of this difference may be at least partly due to the short follow-up (Wilt et al, 2001). This trial found that the leaflet did not increase knowledge of the natural history of untreated early prostate cancer.

We found some evidence that tailored print information was more effective than general information; tailored information increased average cancer knowledge scores by about $11 \%$ compared with no information and $4 \%$ compared with general information after 3 weeks (de Nooijer et al, 2004). Tailored print information modified attitudes towards paying attention to and seeking help for symptoms only very modestly $(1-2 \%$ change in average scores) compared with no information (de Nooijer et al, 2004).

\section{Community-level interventions examining cancer awareness}

Description of studies and interventions We found four studies examining the effectiveness of community-level interventions aiming to increase cancer awareness (Table 2): all were controlled studies, but none used randomisation (Kiekbusch et al, 2000; Skinner et al, 2000; Blumenthal et al, 2005; McCullagh et al, 2005). The interventions were a public education campaign to increase cancer awareness in African-American communities in two US cities (Blumenthal et al, 2005); an educational programme to promote breast cancer awareness in African-American women in one US city (Skinner et al, 2000); a multimedia programme to promote malignant melanoma knowledge sited in a kiosk in a public place in a Swedish village (Kiekbusch et al, 2000) and a health promotion initiative to promote testicular cancer knowledge and self-checking using posters, leaflets and shower gel in UK workplaces, health clubs and leisure centres (McCullagh et al, 2005).

The studies used different outcome measures, one encompassing knowledge, beliefs and attitudes (Blumenthal et al, 2005), the others only knowledge (Kiekbusch et al, 2000; Skinner et al, 2000; McCullagh et al, 2005); only one used a measure that was reported to have been validated (Skinner et al, 2000).

Quality of studies In all the studies, the researchers selected controls appropriately by identifying communities or sites that were likely to have populations with similar characteristics to the intervention communities or sites, but were not likely to be contaminated by the intervention. For two of the studies (the Swedish study of the melanoma interactive multimedia programme, Kiekbusch et al, 2000, and the US study of the breast cancer educational programme, Skinner et al, 2000), the researchers used only one control area. The public education campaign selected two control cities (Blumenthal et al, 2005) and the UK study of the testicular cancer initiative selected four control sites (McCullagh et al, 2005). While the study design in these four studies is stronger than if they were uncontrolled, differences between intervention and control areas can give rise to spurious findings of effectiveness or lack of effectiveness.

Findings The studies examining the effectiveness of the public education campaign in the United States and the effectiveness of the interactive multimedia kiosk in Sweden found no effect on knowledge (Kiekbusch et al, 2000; Blumenthal et al, 2005). The studies of the educational programme for breast cancer in the United States and the UK health promotion initiative for testicular cancer found modest increases in knowledge, the first an increase in average breast cancer knowledge score of about $6 \%$ after 8 months (Skinner et al, 2000) and the second an increase in average testicular cancer knowledge score of $20 \%$ after 6 weeks (McCullagh et al, 2005).

\section{Community-level interventions examining early presentation outcomes}

Description of studies and interventions We found six studies; one interrupted time-series analysis (Catalano et al, 2003) and five before-and-after studies (Rossi et al, 2000; Geczi et al, 2001; 
Table 2 Studies examining the effectiveness of community-level interventions on cancer awareness outcomes

\begin{tabular}{|c|c|c|c|c|c|c|}
\hline Reference & Cancer & Design & Intervention & $\begin{array}{l}\text { Population providing } \\
\text { outcome data }\end{array}$ & Outcome & Results \\
\hline $\begin{array}{l}\text { Blumenthal } \\
\text { et al (2005) }\end{array}$ & $\begin{array}{l}\text { Any } \\
\text { cancer }\end{array}$ & $\begin{array}{l}\text { Controlled study } \\
\text { (non-randomised) comparing: } \\
\text { Areas with black population } \\
\text { in Nashville and Atlanta vs } \\
\text { Areas with black population } \\
\text { in two cities receiving no } \\
\text { campaign }\end{array}$ & $\begin{array}{l}\text { Public education campaign in two } \\
\text { US cities (Nashville and Atlanta) } \\
\text { to increase knowledge of several } \\
\text { cancers in African-American } \\
\text { communities, delivered by } \\
\text { broadcast and print media, } \\
\text { lectures, workshops, lectures, } \\
\text { presentations over I } 8 \text { months } \\
\text { in } 1994-1996 .\end{array}$ & $\begin{array}{l}\text { African-American adults living } \\
\text { in the four cities approached } \\
\text { by random digit dialling } \\
\text { ( } 4053 \text { before intervention; } \\
3914 \text { after intervention) }\end{array}$ & $\begin{array}{l}\text { Knowledge, beliefs } \\
\text { and attitudes towards } \\
\text { cancer risk factors } \\
\text { and screening }\end{array}$ & $\begin{array}{l}\text { No difference. } \\
\text { Quantitative data not } \\
\text { provided. }\end{array}$ \\
\hline $\begin{array}{l}\text { Skinner et al } \\
(2000)\end{array}$ & Breast & $\begin{array}{l}\text { Controlled study } \\
\text { (non-randomised) in one } \\
\text { US city (St Louis) comparing: } \\
\text { one managed social network } \\
\text { for low income elderly } \\
\text { people receiving the } \\
\text { programme vs } \\
\text { one similar managed } \\
\text { social network not } \\
\text { receiving the programme }\end{array}$ & $\begin{array}{l}\text { Educational programme delivered } \\
\text { in small groups by a health } \\
\text { professional to } 32 \text { women } \\
\text { (mainly African-American) } \\
\text { over three sessions, to increase } \\
\text { breast cancer knowledge and } \\
\text { screening uptake and promoting } \\
\text { message dissemination to others } \\
\text { in the social network. }\end{array}$ & $\begin{array}{l}\text { I53 women (mean age 73) } \\
99 \% \text { African-American, } \\
\text { members of the social } \\
\text { network provided data both } \\
\text { before-and-after intervention }\end{array}$ & $\begin{array}{l}\text { Knowledge of breast } \\
\text { cancer symptoms, risk } \\
\text { factors and risk (range } \\
0,8 \text { ) after } 8 \text { months }\end{array}$ & $\begin{array}{l}\text { Higher in group } \\
\text { education programme } \\
\text { vs control networks } \\
4 . \text { I vs } 3.6, P<0.000 \text { I) }\end{array}$ \\
\hline $\begin{array}{l}\text { Kiekbusch } \\
\text { et al (2000) }\end{array}$ & Melanoma & $\begin{array}{l}\text { Controlled study } \\
\text { (non-randomised) in } \\
\text { Sweden comparing: } \\
\text { one village receiving kiosk vs } \\
\text { one similar village not } \\
\text { receiving kiosk }\end{array}$ & $\begin{array}{l}\text { Interactive multimedia programme } \\
\text { housed in kiosk in the centre } \\
\text { of a village (in the pharmacy, } \\
\text { then health centre, then library) } \\
\text { to increase melanoma knowledge } \\
\text { over } 3 \text { years. }\end{array}$ & $\begin{array}{l}\text { Swedish adults aged } 20-59 \\
\text { living in the villages recruited } \\
\text { from population registries } \\
\text { ( } 648 \text { before intervention; } \\
604 \text { after intervention) }\end{array}$ & $\begin{array}{l}\text { Knowledge of } \\
\text { melanoma symptoms, } \\
\text { risk factors, risk, } \\
\text { preventive measures } \\
\text { (range 1, 3) at the } \\
\text { end of intervention }\end{array}$ & $\begin{array}{l}\text { No difference } \\
\text { (kiosk village vs control } \\
\text { village: } \\
\text { Men: } 2.70 \text { vs } 2.68 \text {, } \\
\text { P-value not provided; } \\
\text { women: } 2.72 \text { vs } 2.75 \text {, } \\
\text { P-value not provided) }\end{array}$ \\
\hline $\begin{array}{l}\text { McCullagh } \\
\text { et al (2005) }\end{array}$ & Testicular & $\begin{array}{l}\text { Controlled study } \\
\text { (non-randomised) in the } \\
\text { United Kingdom comparing: } \\
\text { ten sites receiving the } \\
\text { health promotion initiative vs } \\
\text { four sites receiving no } \\
\text { health promotion initiative }\end{array}$ & $\begin{array}{l}\text { Health promotion initiative with } \\
\text { printed shower gel sachets, stickers } \\
\text { and posters displayed in changing } \\
\text { rooms in workplaces, health clubs } \\
\text { and leisure centres, to increase } \\
\text { knowledge of testicular cancer } \\
\text { and promote self-examination, } \\
\text { delivered once to each site. }\end{array}$ & $\begin{array}{l}\text { Men aged } 15-44 \text { attending } \\
\text { workplaces, health clubs } \\
\text { and leisure centres in } \\
\text { United Kingdom } \\
\text { ( } 518 \text { before intervention; } \\
356 \text { after intervention) }\end{array}$ & $\begin{array}{l}\text { Knowledge of testicular } \\
\text { cancer symptoms, risk } \\
\text { and survival (range } 0,5) \\
\text { after } 6 \text { weeks }\end{array}$ & $\begin{array}{l}\text { Higher in health } \\
\text { promotion initiative } \\
\text { sites vs control sites } \\
(4 \text { vs } 3, P=0.014 \text { ) }\end{array}$ \\
\hline
\end{tabular}

MacKie et al, 2003; Leander et al, 2007; Gabram et al, 2008) (Table 3).

The interrupted time-series study examined the effectiveness of an annual media campaign, Breast Cancer Awareness Month, over 23 years in three US cities (Catalano et al, 2003). One beforeand-after study examined the effectiveness of educational presentations at a range of sites aiming to downstage breast cancer at the time of diagnosis in African-American women in a US city (Gabram et al, 2008). The other four studies examined effectiveness of public education campaigns. Two aimed to promote early presentation in malignant melanoma: a poster and leaflet campaign in the West of Scotland (MacKie et al, 2003); and a media campaign followed by a leaflet to every household inviting every adult with risk factors for a skin check in one city in Italy (Rossi et al, 2000). One examined the effectiveness of a national testicular cancer awareness campaign in Hungary (Geczi et al, 2001) and another a national retinoblastoma awareness campaign in Honduras (Leander et al, 2007); both used broadcast and print media, and seminars and presentations to groups.

Three studies collected outcome data on time from symptom discovery to presentation or diagnosis (Geczi et al, 2001; MacKie et al, 2003; Leander et al, 2007). Five studies collected stage at diagnosis as an outcome (Rossi et al, 2000; Catalano et al, 2003; MacKie et al, 2003; Leander et al, 2007; Gabram et al, 2008).

Quality of studies The time-series study was of high quality, the analysis controlling for autocorrelation, secular trends and events that might increase detection of all tumours (such as open enrolment to health insurance plans) by modelling as a function of the incidence of early stage colon cancers in men (Catalano et al,
2003). A before-and-after design is often the only feasible design for evaluating public education campaigns, although this design is intrinsically limited because change in outcome cannot be attributed to the intervention alone. However, in four of the before-and-after studies, the outcomes were measured soon after the intervention (Rossi et al, 2000; Geczi et al, 2001; Leander et al, 2007; Gabram et al, 2008) so changes are fairly likely to be attributable to the intervention. The Scottish melanoma study examined outcomes 10 years after the intervention (MacKie et al, 2003); however, a study examining earlier outcomes of the campaign suggests that the campaign immediately and significantly increased the proportion of malignant melanomas with Breslow thickness $<1.5 \mathrm{~mm}$ and that this was sustained during the $1980 \mathrm{~s}$ (MacKie and Hole, 1992).

Findings The time-series study found that Breast Cancer Awareness Month, over 23 years, led to the detection of 790 more early stage (in situ and local (confined to the breast)) breast cancers (an average of 34 per year) during the quarters in which the month occurred (Catalano et al, 2003). The authors neither report in situ and local cancer separately, nor the proportion identified by screening. The study of educational presentations to downstage breast cancer in African-American women found that it reduced the proportion with advanced disease and increased the proportion with very early disease (Stage 0) (Gabram et al, 2008). The study of the Italian melanoma campaign found a reduction in mean tumour thickness over the period of the campaign compared with the 4 years before (Rossi et al, 2000), and the study of the Scottish melanoma campaign found an increase in the proportion of cases with tumour thickness $<1.5 \mathrm{~mm}$ (MacKie et al, 2003). This study also found an increase in the proportion delaying presentation for $<3$ months. The two other studies examining 
Table 3 Studies examining the effectiveness of community-level interventions on early presentation outcomes

\begin{tabular}{|c|c|c|c|c|c|c|}
\hline Reference & Cancer & Design & Intervention & $\begin{array}{l}\text { Population providing } \\
\text { outcome data }\end{array}$ & Outcome & Results \\
\hline $\begin{array}{l}\text { Catalano } \\
\text { et al (2003) }\end{array}$ & Breast & $\begin{array}{l}\text { Interrupted time-series } \\
\text { analysis }\end{array}$ & $\begin{array}{l}22 \text { annual public education broadcast } \\
\text { and print media campaigns in three } \\
\text { US cities (Atlanta, Detroit and } \\
\text { San Francisco) about nature, } \\
\text { detection and treatment } \\
\text { of breast cancer (Breast Cancer } \\
\text { Awareness Month) over 1975-97. }\end{array}$ & $\begin{array}{l}\text { All cancer registrations } \\
\text { in Atlanta, Detroit, } \\
\text { San Francisco over } \\
23 \text { years }\end{array}$ & $\begin{array}{l}\text { Additional in situ } \\
\text { and local breast } \\
\text { cancers }\end{array}$ & $\begin{array}{l}790 \text { additional } \\
\text { cancers over } \\
23 \text { years }(P<0.05)\end{array}$ \\
\hline $\begin{array}{l}\text { Gabram } \\
\text { et al (2008) }\end{array}$ & Breast & $\begin{array}{l}\text { Before-and-after } \\
\text { study }\end{array}$ & $\begin{array}{l}\text { Educational presentations delivered } \\
\text { to groups (mainly African-American) } \\
\text { by community health advocates in } \\
\text { churches, workplaces, schools, etc, in } \\
\text { one US city (Atlanta) to reduce breast } \\
\text { cancer stage at presentation, during } \\
2001 \text { - } 2004 \text {. }\end{array}$ & $\begin{array}{l}\text { Women diagnosed } \\
\text { with breast cancer ( } 89 \% \\
\text { African-American) in } \\
\text { one Atlanta hospital in } \\
2001(n=113) \text { and } \\
2004(n=128)\end{array}$ & $\begin{array}{l}\text { Proportion with } \\
\text { stage } 0 \\
\text { Proportion with } \\
\text { stage IV }\end{array}$ & $\begin{array}{l}\text { Increased }(12 \% \text { vs } \\
26 \%, P<0.005) \\
\text { Reduced }(17 \% \text { vs } \\
9 \%, P<0.05)\end{array}$ \\
\hline \multirow[t]{2}{*}{$\begin{array}{l}\text { Mackie et al } \\
(2003)\end{array}$} & Melanoma & $\begin{array}{l}\text { Before-and-after } \\
\text { study }\end{array}$ & $\begin{array}{l}\text { Public education campaign in West } \\
\text { of Scotland to encourage early } \\
\text { presentation in melanoma, delivered } \\
\text { by posters and leaflets during } \\
1986-1988 \text {. }\end{array}$ & $\begin{array}{l}\text { Scottish people diagnosed } \\
\text { with melanoma in one } \\
\text { Glasgow clinic in } 1986 \\
(n=125) \text { and } 2001 \\
(n=162)\end{array}$ & $\begin{array}{l}\text { Proportion delaying } \\
\text { presentation after } \\
\text { symptom discovery } \\
\text { three or fewer months }\end{array}$ & $\begin{array}{l}\text { Increased } \\
\text { (16\% vs } 67 \%, 95 \% \\
\text { confidence interval } \\
\text { for difference } \\
42 \% \text { to } 61 \% \text { ) }\end{array}$ \\
\hline & & & & & $\begin{array}{l}\text { Proportion with } \\
\text { tumour thickness } \\
<1.5 \mathrm{~mm}\end{array}$ & $\begin{array}{l}\text { Increased } \\
\text { (38\% vs } 72 \%, 95 \% \\
\text { confidence interval } \\
\text { for difference } \\
23 \% \text { to } 45 \%)\end{array}$ \\
\hline $\begin{array}{l}\text { Rossi et al } \\
(2000)\end{array}$ & Melanoma & $\begin{array}{l}\text { Before-and-after } \\
\text { study }\end{array}$ & $\begin{array}{l}\text { Public education campaign in Padua, } \\
\text { Italy with broadcast and print media } \\
\text { campaign followed by leaflet about } \\
\text { symptoms and risk factors for melanoma } \\
\text { and skin self-examination, inviting adults } \\
\text { to request skin check, delivered by } \\
\text { post to every family in Padua over } \\
\text { |99| -6. }\end{array}$ & $\begin{array}{l}\text { Padua residents diagnosed } \\
\text { with melanoma between } \\
1987-1990(n=79) \text { and } \\
1991-1996(n=137)\end{array}$ & $\begin{array}{l}\text { Mean tumour } \\
\text { thickness }\end{array}$ & $\begin{array}{l}\text { Reduced } \\
(2.0 \mathrm{~mm} \text { vs } \\
1.5 \mathrm{~mm}, P<0.02)\end{array}$ \\
\hline $\begin{array}{l}\text { Geczi et al } \\
(200 I)\end{array}$ & Testicular & $\begin{array}{l}\text { Before-and-after } \\
\text { study }\end{array}$ & $\begin{array}{l}\text { National Hungarian public education } \\
\text { campaign about risk factors, } \\
\text { importance of early detection and } \\
\text { self-examination in testicular cancer, } \\
\text { delivered by broadcast and print } \\
\text { media and at events over } \\
1995-1998 .\end{array}$ & $\begin{array}{l}\text { Hungarian men diagnosed } \\
\text { with testicular cancer in } \\
1994(n=230) \text { and } \\
1998(n=214)\end{array}$ & $\begin{array}{l}\text { Time from symptom } \\
\text { discovery to diagnosis }\end{array}$ & No change \\
\hline $\begin{array}{l}\text { Leander et al } \\
\text { (2007) }\end{array}$ & Retinoblastoma & $\begin{array}{l}\text { Before-and-after } \\
\text { study }\end{array}$ & $\begin{array}{l}\text { National Honduran public education } \\
\text { campaign to increase awareness } \\
\text { of early signs of retinoblastoma } \\
\text { and to encourage early presentation, } \\
\text { delivered by flyers, posters, } \\
\text { broadcast and print media } \\
\text { and seminars during } 2003-2005 \text {. }\end{array}$ & $\begin{array}{l}\text { Honduran children diagnosed } \\
\text { with retinoblastoma in } \\
1995-2003(n=59) \text { and } \\
2003-2005(n=23)\end{array}$ & $\begin{array}{l}\text { Proportion presenting } \\
\text { with advanced disease } \\
\text { Time from symptom } \\
\text { discovery to diagnosis }\end{array}$ & $\begin{array}{l}\text { Reduced }(73 \% \text { vs } \\
35 \%, P=0.002) \\
\text { No change }\end{array}$ \\
\hline
\end{tabular}

time from symptom discovery to diagnosis found that the campaigns had no effect (Geczi et al, 2001; Leander et al, 2007). However, the Honduran retinoblastoma campaign was associated with a reduction in the proportion presenting with advanced disease (Leander et al, 2007).

\section{DISCUSSION}

\section{Summary of findings}

We found limited evidence to inform policy on individual- or community-level interventions to promote cancer awareness. Randomised controlled trials of several individual-level interventions, which included written information (tailored and general), telephone counselling and a computer interactive programme, found modest positive effects on cancer knowledge or attitudes. Follow-up was for 6 months or less for all except one of the trials, so the long-term benefits are not clear. More intensive and tailored interventions are likely to be more effective. We found no evidence to inform policy on interventions delivered to individuals to promote early presentation. We found limited evidence of effectiveness of community-level interventions (small group educational programmes and health promotion programmes in workplaces, health clubs and leisure centres) to promote cancer awareness. We found good evidence that Breast Cancer Awareness Month in the United States promotes diagnosis of breast cancer at an early stage and some evidence that educational interventions by community health advocates and public education campaigns downstage breast cancer, malignant melanoma and retinoblastoma and reduce time from symptom discovery to initial presentation in melanoma. Only for the Scottish malignant melanoma campaign did we find any evidence that the effect was sustained over a number of years.

Our systematic review has identified stronger evidence for interventions to promote cancer awareness and early presentation than the previous report, which found five studies (seven reports) that would have met our inclusion criteria, had we extended our search to studies published earlier (MacDonald et al, 2004). Two of the reports examined earlier outcomes of the Scottish melanoma campaign that we have referred to above (Doherty and MacKie, 1988; MacKie and Hole, 1992). One study (a controlled study 
of a community-level intervention examining early presentation outcomes) examined the effectiveness of a cervical cancer group education intervention in rural India. The intervention increased the proportion of early cervical cancers diagnosed in the intervention area compared with neighbouring areas (Jayant et al, 1995). The remaining four reports examined three interventions aiming to increase malignant melanoma awareness: one individual-level intervention (an educational brochure distributed in the workplace to increase knowledge in Australian men aged 45 years and older) examined in a randomised controlled trial, which found that it increased knowledge of melanoma compared with no brochure after 3 months (Hanrahan et al, 1995) and two fairly small-scale UK public education campaigns, neither of which found good evidence of a reduction in tumour thickness after the campaigns, although this may have been due to small numbers of incident cancers (Whitehead et al, 1989; Graham-Brown et al, 1990; Healsmith et al, 1993).

\section{Strengths and weaknesses of the review}

Our study brings together the available evidence of effectiveness of interventions to promote cancer awareness and early presentation. Our search strategy was pragmatic and aimed to be specific, but did not include the 'grey' literature (that not published in peerreviewed journals). There is some evidence that more comprehensive search strategies have little effect on the overall result of systematic reviews and may introduce bias by including studies with weaker designs (Egger et al, 2003). However, in systematic reviews of social interventions, such as public education campaigns or health promotion initiatives, searching databases other than the standard biomedical ones may uncover important studies (Ogilvie et al, 2005). While we did not search other databases, we relaxed our study design inclusion criteria for evaluations of community-level interventions, recognising that controlled trials, and particularly randomised controlled trials, are more difficult to carry out.

Searching databases for studies of any kind of intervention to promote cancer awareness or early presentation is difficult because the search terms cannot focus on the intervention itself, unlike a search for studies of the effectiveness of a drug or a particular type of complex intervention. A systematic review of interventions to communicate risk also documented this difficulty (Matthews et al, 1999). It is possible that we missed some studies because of the difficulties of designing a search with a high level of sensitivity and specificity.

Knowledge of screening, screening uptake and self-checking behaviour - for example breast checking (including breast selfexamination) or testicular checking - may be considered to be important elements of cancer awareness. We excluded studies of interventions examining only the outcomes of knowledge or uptake of breast or cervical screening because these have been covered by other studies (Bonfill Cosp et al, 2001; Forbes et al, 2002). We excluded studies examining outcomes of self-checking behaviour because the effectiveness of different modes of selfexamination has not been established.

\section{Strengths and weaknesses of the available evidence}

For interventions delivered at an individual level, we found five fairly well-conducted randomised controlled trials examining awareness outcomes. None examined early presentation outcomes. In two of the trials, only one or two relevant knowledge questions were included as outcomes (Wilt et al, 2001; Rimer et al, 2002) because the main aim of the interventions were not, primarily, to increase cancer awareness to promote early presentation, but to promote breast cancer screening in one (Rimer et al, 2002) and decision making about prostate cancer screening in the other (Wilt et al, 2001). The other three interventions did aim mainly to increase awareness to promote early presentation in malignant melanoma (Glazebrook et al, 2006) oral cancer (Boundouki et al, 2004) and a range of cancers (de Nooijer et al, 2004).

Cancer awareness was measured in a number of ways. Only one trial used a knowledge scale that was reported to have been validated (Boundouki et al, 2004). Owing to this and the short follow-up in all except one trial, it is not possible to assess whether the increases in awareness would be sufficiently comprehensive, large or sustained to lead to significant behavioural change in the event of symptom discovery.

One of the difficulties of evaluating community-level interventions using the positivist methods conventional in medical research is that these methods are less widely accepted by social science and health promotion disciplines involved in designing them (Green and Tones, 1999; Ogilvie et al, 2005). Another is that the interventions are usually complex (multi-component) and dependent on context, and controlled trials, let alone randomised controlled trials, are often very difficult (Thomson et al, 2004). We found four controlled studies (not using randomisation) of community-level interventions to increase cancer awareness. Interpretation of findings is limited by the relatively weak study design. The studies used a range of outcome measures; only one used a measure that was reported to be validated (Skinner et al, 2000). Two studies found no significant effects on cancer awareness (Blumenthal et al, 2005) (Kiekbusch et al, 2000); whether this is due to intrinsic lack of effectiveness of the interventions, invalid outcome measures or to limitations of study design is unknown. Two found increases in cancer awareness: one 8 months after an intensive educational programme (Skinner et al, 2000) and one 6 weeks after a poster and leaflet initiative (McCullagh et al, 2005). It is likely that the outcomes were attributable to the interventions, but we cannot be sure of this because of the limitations of study design.

Overall, community-level interventions to promote early presentation provided some evidence of effectiveness for breast cancer, melanoma and retinoblastoma. Five studies suggested that educational campaigns may lead to downstaging cancer (Rossi et al, 2000; Catalano et al, 2003; MacKie et al, 2003; Leander et al, 2007; Gabram et al, 2008); however, all were uncontrolled, so the results cannot be reliably attributed to the intervention. On the other hand, outcomes were measured soon after the intervention, so it is more likely that the improvement can be attributed to it. Another problem with interpreting the findings is that it is not possible to attribute the downstaging of cancer to the effect of the campaigns on the public only - all the interventions are likely to have raised health professional awareness as well; in fact, most were specifically designed to do so.

The finding that Breast Cancer Awareness Month (Catalano et al, 2003) increased diagnosis of early stage tumours may be at least partly due to increased mammography uptake during the month or soon after, rather than early presentation with symptoms, so we cannot tell which kind of behaviour was promoted by the intervention. This is also true of the finding that educational presentations increased the proportion with stage 0 breast cancer (Gabram et al, 2008). The benefit of detecting more stage 0/in situ cancers in terms of breast cancer outcomes is unknown, as some of the women with these cancers may never have experienced clinical problems and may have received unnecessary investigations.

Few studies examined duration of symptoms from discovery to initial presentation (Geczi et al, 2001; MacKie et al, 2003; Leander et al, 2007) and two found no effect (Geczi et al, 2001; Leander et al, 2007). It is possible that these two studies found no effect on duration of symptoms because the campaigns may have advanced both the average date of symptom discovery and the average date of presentation, which would lead to presentation at 
an earlier stage, but would have no effect on duration of symptoms.

\section{Implications}

We found some evidence that interventions delivered at an individual level can promote cancer awareness over the short term, but no evidence that these promote early presentation with cancer symptoms. Future research evaluating individual-level interventions to promote cancer awareness should attempt to use study designs that generate high-quality evidence, measure outcomes over a longer term (months/years) and attempt to measure behavioural and stage outcomes, as well as knowledge and attitudes. We also highlight the need for standardised and validated measures of cancer awareness for different cancers, similar to the Cancer Research UK Cancer Awareness Measure supported by the National Awareness and Early
Diagnosis Initiative (Stubbings et al, 2009). There is also a need for standardised and validated measures of duration of symptoms.

We found limited evidence that intensive education campaigns may lead to greater cancer awareness and earlier presentation over the short term. However, what exactly a campaign needs to include to make it work, to make it work over the longer term and in different settings and to make it work cost-effectively are not clear and warrant more research.

\section{Conflict of interest}

The authors declare no conflict of interest.

Supplementary Information accompanies the paper on British Journal of Cancer website (http://www.nature.com/bjc)

\section{REFERENCES}

Blumenthal DS, Fort JG, Ahmed NU, Semenya KA, Schreiber GB, Perry S, Guillory J (2005) Impact of a two-city community cancer prevention intervention on African Americans. J Natl Med Assoc 97: $1479-1488$

Bonfill Cosp X, Marzo Castillejo M, Pladevall Vila M, Marti J, Emparanza JI (2001) Strategies for increasing the participation of women in community breast cancer screening. Cochrane Database Syst Rev, Issue 1. Art. No. CD002943. DOI: 10.1002/14651858.CD002943

Boundouki G, Humphris G, Field A (2004) Knowledge of oral cancer, distress and screening intentions: longer term effects of a patient information leaflet. Patient Educ Couns 53: $71-77$

Catalano R, Winett L, Wallack L, Satariano W (2003) Evaluating a campaign to detect early stage breast tumors in the United States. Eur J Epidemiol 18: 545-550

De Nooijer J, Lechner L, Candel M, de Vries H (2004) Short- and long-term effects of tailored information versus general information on determinants and intentions related to early detection of cancer. Prev Med 38: $694-703$

Doherty VR, MacKie RM (1988) Experience of a public education programme on early detection of cutaneous malignant melanoma. BMJ 297: $388-391$

Downing A, Prakash K, Gilthorpe MS, Stefoski MJ, Forman D (2007) The effect of socioeconomic background on stage at diagnosis, treatment pattern and survival in women with invasive breast cancer. Br J Cancer 96: 836-840

Egger M, Juni P, Bartlett C, Holenstein F, Sterne J (2003) How important are comprehensive literature searches and the assessment of trial quality in systematic reviews? Empirical Study Health Technol Assess 7: 1-76

Forbes CA, Jepson RG, Martin-Hirsch PPL (2002) Interventions targeted at women to encourage the uptake of cervical screening. Cochrane Database Syst Rev, Issue 3. Art. No. CD002834. DOI: 10.1002/14651858.CD002834

Gabram SG, Lund MJ, Gardner J, Hatchett N, Bumpers HL, Okoli J, Rizzo M, Johnson BJ, Kirkpatrick GB, Brawley OW (2008) Effects of an outreach and internal navigation program on breast cancer diagnosis in an urban cancer center with a large African-American population. Cancer 113: 602-607

Gatta G, Capocaccia R, Sant M, Bell CMJ, Coebergh JWW, Damhuis RAM, Faivre J, Martinez-Garcia C, Pawlega J, de Leon MP, Pottier D, Raverdy N, Williams EMI, Berrino F (2000) Understanding variations in survival for colorectal cancer in Europe: a EUROCARE high resolution study. Gut 47: $533-538$

Geczi L, Gomez F, Horvath Z, Bak M, Kisbenedek L, Bodrogi I (2001) Three-year results of the first educational and early detection program for testicular cancer in Hungary. Oncology 60: 228-234

Glazebrook C, Garrud P, Avery A, Coupland C, Williams H (2006) Impact of a multimedia intervention 'Skinsafe' on patients' knowledge and protective behaviors. Prev Med 42: 449-454

Goldsmith M, Bankhead C, Austoker J (2006) Improving the Quality of the Written Information Sent to Women about Cervical Screening: EvidenceBased Criteria for the Content of Letters and Leaflets NHS Cancer Screening Programmes NHSCSP Publication No. 26 NHS Screening Programmes: Sheffield
Graham-Brown RA, Osborne JE, London SP, Fletcher A, Shaw D, Williams B, Bowry V (1990) The initial effects on workload and outcome of a public education campaign on early diagnosis and treatment of malignant melanoma in Leicestershire. Br J Dermatol 122: 53-59

Green J, Tones K (1999) For debate towards a secure evidence base for health promotion. J Public Health 21: 133-139

Hanrahan PF, Hersey P, Watson AB, Callaghan TM (1995) The effect of an educational brochure on knowledge and early detection of melanoma. Aust J Public Health 19: 270-274

Healsmith MF, Graham-Brown RA, Osborne JE, London SP, Fletcher A (1993) Further experience of public education for the early diagnosis of malignant melanoma in Leicestershire. Clin Exp Dermatol 18: $396-400$

Jack RH, Davies EA, Moller H (2009) Breast cancer incidence, stage, treatment and survival in ethnic groups in South East England. $\mathrm{Br} J$ Cancer 100: $545-550$

Jayant K, Rao RS, Nene BM, Dale PS (1995) Improved stage at diagnosis of cervical cancer with increased cancer awareness in a rural Indian population. Int J Cancer 63: 161-163

Kiekbusch S, Hannich HJ, Isacsson A, Johannisson A, Lindholm LH, Sager E, Slaug B, Moller TR (2000) Impact of a cancer education multimedia device on public knowledge, attitudes, and behaviors: a controlled intervention study in Southern Sweden. J Cancer Educ 15: $232-236$

Leander C, Fu LC, Pena A, Howard SC, Rodriguez-Galindo C, Wilimas JA, Ribeiro RC, Haik B (2007) Impact of an education program on late diagnosis of retinoblastoma in Honduras. Pediatr Blood Cancer 49: $817-819$

MacDonald S, Macleod U, Mitchell E, Weller D, Campbell N, Mant D (2004) Factors Influencing Patient and Primary Care Delay in the Diagnosis of Cancer Project M0005101440 University of Glasgow, Final report to the Department of Health: Glasgow, Scotland

MacKie RM, Bray CA, Leman JA (2003) Effect of public education aimed at early diagnosis of malignant melanoma: cohort comparison study. BMJ 326: 367

MacKie RM, Hole D (1992) Audit of public education campaign to encourage earlier detection of malignant melanoma. BMJ 304 $1012-1015$

Matthews EJ, Edwards AG, Barker J, Bloor M, Covey J, Hood K, Pill R, Russell I, Stott N, Wilkinson C (1999) Efficient literature searching in diffuse topics: lessons from a systematic review of research on communicating risk to patients in primary care. Health Libr Rev 16: $112-120$

McCullagh J, Lewis G, Warlow C (2005) Promoting awareness and practice of testicular self-examination. Nurs Stand 19: 41-49

Ogilvie D, Hamilton V, Egan M, Petticrew M (2005) Systematic reviews of health effects of social interventions: 1 . Finding the evidence: how far should you go? J Epidemiol Community Health 59: 804-808

Ramirez AJ, Westcombe AM, Burgess CC, Sutton S, Littlejohns P, Richards MA (1999) Factors predicting delayed presentation of symptomatic breast cancer: a systematic review. Lancet 353: 1127-1131 
Rimer BK, Halabi S, Sugg Skinner C, Lipkus IM, Strigo TS, Kaplan EB, Samsa GP (2002) Effects of a mammography decision-making intervention at 12 and 24 months. Am J Prev Med 22: 247-257

Rossi CR, Vecchiato A, Bezze G, Mastrangelo G, Montesco MC, Mocellin S, Meneghetti G, Mazzoleni F, Peserico A, Nitti D, Lise M (2000) Early detection of melanoma: an educational campaign in Padova, Italy. Melanoma Res 10: $181-187$

Sant M, Aareleid T, Artioli ME, Berrino F, Coebergh JW, Colonna M, Forman D, Hedelin G, Rachtan J, Lutz JM, Otter R, Raverdy N, Plesko I, Primic MZ, Tagliabue G (2007) Ten-year survival and risk of relapse for testicular cancer: a EUROCARE high resolution study. Eur J Cancer 43: 585-592

Sant M, Allemani C, Capocaccia R, Hakulinen T, Aareleid T, Coebergh JW, Coleman MP, Grosclaude P, Martinez C, Bell J, Youngson J, Berrino F (2003) Stage at diagnosis is a key explanation of differences in breast cancer survival across Europe. Int J Cancer 106: 416-422
Skinner CS, Arfken CL, Waterman B (2000) Outcomes of the learn, share \& live breast cancer education program for older urban women. $A m J$ Public Health 90: 1229-1234

Stubbings S, Robb K, Waller J, Ramirez A, Austoker J, Macleod U, Hiom S, Wardle J (2009) Development of a measurement tool to assess public awareness of cancer. Br J Cancer 101(Suppl 2): S13-S17

Thomson H, Hoskins R, Petticrew M, Ogilvie D, Craig N, Quinn T, Lindsay G (2004) Evaluating the health effects of social interventions. BMJ 328: $282-285$

Whitehead SM, Wroughton MA, Elwood JM, Davison J, Stewart M (1989) Effects of a health education campaign for the earlier diagnosis of melanoma. Br J Cancer 60: 421-425

Wilt TJ, Paul J, Murdoch M, Nelson D, Nugent S, Rubins HB (2001) Educating men about prostate cancer screening. A randomized trial of a mailed pamphlet. Eff Clin Pract 4: 112-120 